\title{
Kimian states and the grammar of predicative adjectives
}

STEFAN ENGELBERG

\section{Introduction ${ }^{1}$}

Maienborn (this volume) presents a proposal on how to deal with stative expressions which makes the following claims:

(i) There are two types of stative expressions, those denoting Davidsonian states (sit, stand, sleep), which constitute a subtype of Davidsonian eventualities, and Kimian states (know, hate, resemble, and all expressions introduced by the copula), which are of a different ontological sort. This distinction is not tied to a distinction between stage-level and individual-level predicates.

(ii) Expressions introducing Davidsonian states behave like eventdenoting expressions and are different from expressions introducing Kimian states with respect to a number of linguistic phenomena (embedding under perception verbs, modification by locative, manner, and instrumental adverbials, interpretation of certain degree modifiers). Kimian states can be temporally modified, anaphorically referred to, and in German they can enter the dabeiconstruction.

(iii) While Davidsonian eventualities are spatio-temporal entities, Kimian states have a more abstract nature. In contrast to the more concrete ontological sort of eventualities, they don't have a spatial dimension, and in contrast to the more abstract ontological sort of facts, they have a temporal dimension. Maienborn conceives of

1 I am grateful to Jennifer R. Austin for helpful comments. 


\section{Stefan Engelberg}

Kimian states as "abstract objects for the exemplification of a property $\mathrm{P}$ at a holder $\mathrm{x}$ and a time t."

(iv) The grammatical category of verbs is not confined to a particular sort of referential argument. While verbs are either Davidsonian or Kimian predicates, lexical predicates that depend on a copula don't make ontological choices on their own. It is always the copula that introduces a Kimian state argument.

In the following section I mainly want to comment on (iii) and (iv). In doing that, I will try to refine some ideas about the ontological nature of Kimian states and I will challenge the assumption that it is the copula which introduces the state argument.

\section{Identity criteria for Kimian states}

The conception of states as presented by Maienborn goes back to Kim's (1969, 1976) exploration of the nature of events. Although his event conception has proven to be too unspecific and, in its preferred interpretation, does not reflect the rather concrete nature of events, Maienborn's use of Kim's event conception for semi-concrete entities like states seems quite promising. However, there is a problem with Kim's idea that carries over to Maienborn's proposal, and it is this problem that I want to address here.

As has been common in event ontology, Kim's investigation into events aims at stating identity criteria for events. Identity criteria explicate the conditions under which two entities are the same, or, in other words, under which conditions two variables $a$ and $b$ stand for the same entity. This procedure is guided by an idea about the nature of the concept of "entity" as something that is countable and that therefore requires distinctness. In order to count events, one has to know whether $a$ and $b$ are identical and therefore count as one or whether they are distinct and thereby two.

Identity criteria are usually classified as fine-grained vs. coarse-grained. A coarse-grained identity criterion for events identifies events via their spatio-temporal extension. According to this criterion, all four sentences in (1) report the same event. Fine-grained identity criteria conceive of 
events more as almost proposition-like entities. All four sentences in (1) would then be about different events. The degree of moderate finegrainedness that seems appropriate for the explanation of many linguistic phenomena requires an identity criterion that renders the events in (1a) through (1c) as the same event and establishes (1d) as a distinct event. Establishing such a criterion has proven very difficult (see Engelberg 2000: 215ff).

(1) a. The ball rotated from three to four o'clock

b. The red ball rotated from three to four o'clock

c. The ball spun around its axis from three to four o'clock

d. The ball warmed up from three to four o'clock

Reformulated in terms of an identity criterion, Maienborn's conception of Kimian states look like this $([\mathrm{x}, \mathrm{P}, \mathrm{t}]$ meaning ' $x$ having the property $P$, which constitutes the state, at time $\left.t^{\prime}\right)$ :

(2) Let us assume that $\mathrm{k}^{1}$ and $\mathrm{k}^{2}$ are Kimian states, $\mathrm{k}^{1}$ is $\left[\mathrm{x}^{1}, \mathrm{P}^{1}, \mathrm{t}^{1}\right]$, and $\mathrm{k}^{2}$ is $\left[\mathrm{x}^{2}, \mathrm{P}^{2}, \mathrm{t}^{2}\right]$, then: $\mathrm{k}^{1}$ and $\mathrm{k}^{2}$ are identical iff $\mathrm{x}^{1}=\mathrm{x}^{2}, \mathrm{P}^{1}=\mathrm{P}^{2}$, and $\mathrm{t}^{1}=\mathrm{t}^{2}$.

One feature of this conception of states is that it extensionalizes over the time and the holder of the state; i.e. the way the time and the holder of the state are described does not influence the identity of the state. This, I think, supports conclusions which seem to be straightforward. Let us assume that (3a) through (3e) are true. From that, we can infer (3f). The state $z^{1}$ described in (3a) is identical to the state $z^{2}$ described in (3b) since $x^{1}$ (Opus) is extensionally identical to $x^{2}$ (the tuba player of Deathtöngue), $t^{1}$ (noon on July $18^{\text {th }}$ ) is extensionally identical to $t^{2}$ (noon last Sunday) and $P^{1}$ and $P^{2}$ are both HAPPY. Now, (i) if $z^{1}=z^{2}$ and (ii) if $z^{1}$ is a state that holds to high degree and (iii) according to Leibniz' Law identical entities share all properties, we conclude that that $z^{2}$ also holds to a high degree. $^{2}$

2 This is a rather sloppy way to talk about degrees, but it will do here for the sake of the argument. 


\section{Stefan Engelberg}

(3) a. Opus was happy at noon on July $18^{\text {th }}$

b. The tuba player of Deathtöngue was happy at noon last Sunday

c. Opus is the tuba player of Deathtöngue

d. Last Sunday was July $18^{\text {th }}$

e. Actually, Opus was very happy at noon on July $18^{\text {th }}$

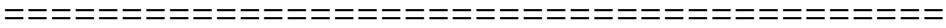

f. The tuba player of Deathtöngue was very happy at noon last Sunday

While this is a desirable result, which we get if we assume that HAPPY is indeed the property that constitutes the state, it still leaves us with a question that Kim himself had difficulties answering, namely the question how we can in general determine $P$. Although Maienborn is not explicit about this, her approach suggests that $P$ is whatever follows the copula. E.g., for (4a) she assumes a representation like (4b), where " $\approx$ " relates a discourse referent for an abstract object to a Discourse Representation Structure that characterizes it.

(4) a. der Brief in einem Umschlag sei'the letter to be in an envelope'

b. $\lambda \mathrm{z}[\mathrm{v}, \mathrm{u} \mid \mathrm{z} \approx[\operatorname{LOC}(\mathrm{v}, \operatorname{IN}(\mathrm{u})), \operatorname{ENVELOP}(\mathrm{u})], \operatorname{LETTER}(\mathrm{v})]$

If we assume that " $\approx$ " introduces what might be thought of as $P$, we run into problems since individuals introduced by NPs below the copula like Umschlag in (4a) are not extensionalized over, but are part of the stateconstituting property. This would lead to an undesirable consequence. Let us again assume that Opus is the tuba player of Deathtöngue. Then, (5a) and (5b) would describe the same state since we extensionalize over the subject referents and the state constituting property is the same in both cases (RELATED TO GEORGE).

(5) a. Opus ist mit George verwandt

'Opus is related to George'

b. Der Tubaspieler von Deathtöngue ist mit George verwandt 'The tuba player of Deathtöngue is related to George'

(6a) and (6b), on the other hand, would be about different states, since the predicates following the copula are different: RELATED TO OPUS vs. RELATED TO THE TUBA PLAYER OF DEATHTÖNGUE. This is certainly counterintuitive. 
(6) a. George ist mit Opus verwandt

'George is related to Opus'

b. George ist mit dem Tubaspieler von Deathtöngue verwandt

'George is related to the tuba player of Deathtöngue'

Furthermore, it would follow that (5a) and (6a) report different states because of their different state-constituting properties (RELATED to GEORGE vs. RELATED to OpUs). Thus, even logically equivalent sentences like (5a) and (6a) could be about different states. This, in turn, would lead to a conception of states that would make states even more fine-grained than propositions. This is certainly not desired by Maienborn, who wants to locate the degree of abstractness of states between eventualities and facts. Thus, a first refinement of Maienborn's idea of states should include the requirement that individuals introduced below the copula have to be extensionalized over. The state-constituing property in (5) and (6) might thus be RELATED TO $\mathrm{x}$. Then the four sentences would be about the same state. $^{3}$

There is yet more to be said about state-constituting properties. In the argumentation connected to (3) I have presupposed that happy and very happy do indeed characterize the same state. Although this seems intuitively plausible, it doesn't follow from the Kimian-Maienbornian identity

3 Another problem is connected to this one. Not only would (i) and (ii) be about the same state and (iii) and (iv) counterintuitively about different ones under this interpretation of $P$, but the copula-adjective construction ähnlich sein would lead to a different representation than the corresponding verb ähneln. Although both mean 'be similar / resemble' and denote Kimian states, the representation for the verbal version given by Maienborn in her article is (v), while, according to the compositional approach she presents, the adjectival version would yield (vi). This suggests that the two states in (v) and (vi) are characterized differently, which is counterintuitive:

(i) Opus ist George ähnlich 'Opus is similar to / resembles George'

(ii) Der Tubaspieler von Deathtöngue ist George ähnlich

'The tuba player of Deathtöngue is similar to / resembles George'

(iii) George ist Opus ähnlich 'George is similar to / resembles Opus'

(iv) George ist dem Tubaspieler von Deathtöngue ähnlich 'George is similar to / resembles the tuba player of Deathtöngue'

(v) Opus George ähnlich sei-: $\lambda z[v, u \mid z \approx[\operatorname{resemble}(v, u)$, George(u)], Opus(v)]

(vi) Opus George ähnel-: $\lambda z[v, u \mid z \approx[\operatorname{resemble}(v, u)]$, George(u), Opus(v)] 
criterion. If we want to identify these states, it looks like we should restrict $P$ to some nuclear predicate within the post-copular phrase, e.g. in (3e) the mere adjective itself. But even that might still yield states that are too fine-grained, as we will see.

Kim was aware of the indeterminacy in his event criterion and made some suggestions on how to deal with it. Interestingly, he suggested that sentences like (7a) and (7b) are actually about the same event and that is blue and has the color of the sky pick out the same event-constituting property. ${ }^{4}$
(7) a. The shirt is blue
b. The shirt has the color of the sky

Despite Kim's remarks pertaining to (7), in general, he adopted a more fine-grained stance towards the role of $P$ in his event conception. In particular, Kim (1976: 162) considered tying the choice of $P$ to causal differences, i.e. $P^{l}$ and $P^{2}$ constitute different events if they make a causal difference. I won't go into that here. The numerous problems that emerge from identy criteria which are linked to causal properties have been discussed elsewhere (cf. Bennett 1988, Eckardt 2000). Instead I want to come to back to one of the phenomena Maienborn discusses as support for the introduction of Kimian states, which is the dabei-construction that relates states and / or events and expresses something like accompaniment. I think this construction might be employed for an additional purpose, namely for operationalizing our intuition about state indentities. What dabei does is presuppose that the states it connects are different. Thus, in those cases where we would intuitively say that we are talking about different states, the dabei-construction is unproblematic. In those other cases, where the same state seems to be reported by the two conjuncts, the dabei-construction is clearly less acceptable:

(8) a. Der Himmel ist blau und dabei bewölkt

"The sky is blue and "there-at" cloudy (accompanied by cloudiness)'

4 Kim included states in his event conception. 
b. "Der Himmel ist blau und dabei sehr blau

'The sky is blue and "there-at" very blue'

c. "Der Himmel ist blau und dabei azur

'The sky is blue and "there-at" azure'

d. ${ }^{\#}$ Der Himmel ist blau und dabei von der Farbe einer

Babymütze

'The sky is blue and "there-at" of the color of a baby hat'

Thus, the dabei-construction might work as a state-distinguishing device. This of course cannot replace an identity-criterion, rather it shows what the criterion will have to achieve.

Thus, if we assume that the state we talk about in (8a) through (8c) is the "color-state" of the sky, then all predicates describing its color, although denoting different properties, serve to constitute the same state, i.e. they define the same state-constituting property. ${ }^{5}$ All predicates pertaining to its "cloud-state" constitute a different state. This, at least, is the state conception that is needed for the semantic treatment of the dabei-construction. ${ }^{6}$

Finally, quite similar to the discussion of events in (1), it seems plausible that we identify the states in (9a) through (9c) as the same, but conceive of (9d) as pertaining to a different state. This makes the degree of fine-grainedness of states look rather similar to the one that is usually strived for in the domain of events.

5 It should be noted that $P$ is the property that the state exemplifies, and not a property of the state.

6 As we have seen, Kim's criterion is as fine-grained as we want to have it, depending on what we allow to be the constituting property $P$. His idea about constituting event properties (here called "generic events") is reflected in the following citation: "[ $\ldots]$ the basic generic events may be best picked out relative to a scientific theory, whether the theory is a common-sense theory of the behavior of middle-sized objects or a highly sophisticated physical theory. They are among the important properties, relative to the theory, in terms of which lawful regularities can be discovered, described, and explained. The basic parameters in terms of which the laws of the theory are formulated would, on this view, give us our basic generic events, and the usual logical, mathematical, and perhaps other operations on them would yield complex, defined generic events. We commonly recognize such properties as motion, colors, temperatures, weights, pushing, and breaking as generic events and states, but we must view this against the background of our commonsense explanatory and predicative scheme of the world around us." (Kim 1976: 162163) 
(9) a. The sky was blue from three to four o'clock

b. The sky over Streymoy was blue from three to four o'clock

c. The sky was of a bright bluish baby hat color from three to four o'clock

d. The sky was cloudless from three to four o'clock

Conclusion: Although states, in lacking a spatial dimension, are more abstract entities than events, they are probably not more fine-grained. To establish these assumptions, further work on the semantic treatment of the phenomena discussed by Maienborn and on the specification of the critical " $P$-factor" in her identity criterion for states is needed.

\section{Adjectival predication cross-linguistically}

Beyond the discussion of how Kimian states are linguistically made use of and how they are ontologically founded, the question arises how state arguments are projected. Maienborn, as well as a number of other authors she discusses, assumes that it is the copula which introduces the state argument. The APs, NPs, and PPs embedded in the copula construction enter the derivation without any situation-related argument. Although Maienborn's claims do not go beyond German, English, and Spanish and their respective copulas sein, be, and ser, I will have a look at a couple of other languages to see how far this idea might be taken. I will restrict myself to adjectives in predicative position. Not only is the category of adjectives known to show wide typological variation with respect to its grammatical status, but the way adjectives enter into predicative constructions also varies considerably cross-linguistically. The following thoughts rely on the assumption that the difference between Kimian and Davidsonian states is a universal one - which is not explicitely claimed by Maienborn - and that linguistic phenomena similar to the ones discussed by Maienborn which relate to this distinction can be found in other languages, too.

With respect to the expression of "adjectival" meanings in predicative position, the following types of languages shall be distinguished: (i) languages in which "adjectival" meanings are expressed by verbs, (ii) languages in which "adjectival meanings" are expressed by adjectives, yet these adjectives are not introduced by a copula, (iii) languages in which 
some predicative adjectives need a copula and others don't, (iv) languages in which the copula is optional. ${ }^{7}$

Ad (i): It has often been argued that numerous languages do not distinguish between adjectives and verbs. Even if this claim seems to have been overstated a bit (cf. Dixon 1994), it is a fact that there are some languages which do not have a separate category of adjectives and there are a couple more in which adjectives in predicative position are treated like verbs. A language in which there is no morphosyntactic distinction between "adjectival" and "verbal" concepts either in a predicative position or in an attributive one is Manipuri, a Tibeto-Burman language (cf. Bhat and Ningomba 1997). ${ }^{8}$ In predicative position both take typical verbal affixes (10); in attributive position (11) both appear in a sort of relative clause:

a. məhak-nə məthəntə layrik

he-NOM self book

pi-jə-y (from Bhat and Ningomba 1997: 42)

give-REFL-NONFUT ${ }^{9}$

'He gave the book to himself'

b. məhak məthəntə saw-jə-y

he self angry-REFL-NONFUT

'He is angry with himself'

(11) a. ca-də-bə mi nay

eat-NEG-INF man ill

'The man who did not eat is ill'

b. pən-də-bə mi nay

stupid-NEG-INF man ill

'The man who is not stupid is ill' 10

$7 \quad$ A further type not discussed here are languages in which all adjectives can enter a predicative construction with a copula and a different predicative construction without; this can be found in Dravidian languages like Telugu or Kannada (cf. Stassen 2001: 582 $583)$.

8 There are some minor differences between "adjectival" and "verbal" verbs, but they do not exceed the amount of variation that one would expect to find within a part of speech anyways.

9 The affix glossed as Nom does only appear if the subject is the controller of the action.

10 In contrast to verb / adjectives, nouns get introduced by a copula (cf. Bhat and Ningomba 1997: 39). 
That some languages construe "adjectival meanings" as verbs is, on the one hand, not problematic for Maienborn's approach, since she assumes per se that Kimian state arguments can be introduced not only by the copula but also by full verbs. For Manipuri, one could simply assume that all verbs opt for one or the other sort of argument: a Davidsonian argument or a Kimian argument. ${ }^{11}$ On the other hand, this would of course suggest that it is the lexical meaning of predicates in Manipuri that decides the ontological nature of the entity they are predicates of. This leaves us with the question why we are supposed to assume that a concept like GOOD is expressed by a state-denoting expression in Manipuri, $(\lambda x \lambda z[z \approx \operatorname{GOOD}(x)])$, but - according to Maienborn - not in German $(\lambda x[\mathrm{GOOD}(\mathrm{x})])$.

Ad (ii): Cebuano, an Austronesian language, exhibits a distinction between adjectives and verbs and allows adjectives in predicative constructions (Bunye and Yap 1971). It doesn't have a copula to introduce adjectival or nominal predicates, though:
a. Taas ang dalaga ${ }^{12}$ tall TOP lady
'The lady is tall'
b. Ako ang dalaga I TOP lady
'I am the lady'

(from Bunye and Yap 1971: 65) 
This suggests that state arguments are projected from the lexical adjectives and nouns themselves, from which follows that in contrast to Manipuri and to what Maienborn assumes for German, it is not only verbs that introduce state arguments. ${ }^{13}$

Ad (iii): Japanese distinguishes two classes of "adjectival" predicates. Predicates of the first class have more of a verbal nature in that they take inflectional endings (e.g. for tense), predicates of the second class are accompanied by a copula in predicative position and thus have more of a nominal nature: ${ }^{14}$
a. Ano hito wa
(from Shibatani 1990: 215-216)
utukusi-i
beautiful-PRES
'That person is beautiful'
b. Ano hito wa kirei da
that person
'That person is pretty'

The class membership of "adjectival" predicates is mainly dependent on their etymological status; the numerous loans (predominantly from Chinese) use the copula-construction (13b) while other, in particular native "adjectival" predicates, inflect as in (13a). To a lesser extent, phonological conditions also play role. Since class membership does not depend on semantic criteria, it seems unlikely that both classes differ in that only one of them provides a state argument. Thus, if one wanted to maintain an approach that leaves it to the copula to introduce the state argument instead of equipping the lexical predicates themselves with Kimian states, a separate solution would have to be found for the "verbal adjectives".

13 I will not discuss options here in which the state argument would be introduced by a functional head.

14 The representation in (13) follows traditional assumptions. There is a long-standing debate about the categorial status of these two types of predicates - whether they are verbs vs. nouns or whether one or both of them are adjectives - as well as about the status of the copula - whether both constructions contain a copula, only the $d a$-construction, or none of them. Cf. the discussion in Ohkado (1991), Bhat (1994) and Namai (2002). 


\section{Stefan Engelberg}

Ad (iv): We might of course continue assuming that different types of languages have different ways of introducing the Kimian argument. Dixon (1994) provides a typology which is mainly centered around the question in how far adjectives behave like nouns or like verbs. The type-1-class languages treat adjectives more like nouns. In these languages, adjectives in attributive position agree with the noun they modify in typical nounlike features (e.g., gender, noun class, case, number), while in predicative position they are typically accompanied by a copula. German and Spanish obviously belong to this type, while English adjectives are less nounlike in not showing agreement. One might wonder if the idea that it is the copula that introduces the Kimian argument can be defended exceptionlessly for languages of Dixon's type 1. But Slavic languages cast doubt on this assumption. In Russian, the copula is realized only in past and future tense, while in present tense sentences the copula cannot occur:

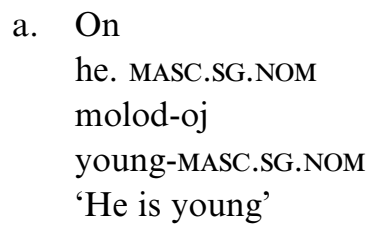

a. On

he. MASC.SG.NOM molod-oj young-MASC.SG.NOM 'He is young' (from Nichols 1981: 292)

b. On byl molod-oj he. MASC.SG.NOM was young-MASC.SG.NOM 'He was young'

If the copula is missing sometimes, where does the Kimian argument come from? Two possible answers are at hand: the first answer would be that maybe there is no Kimian argument in copulaless sentences in Russian. This seems to be unlikely, though, since to my knowledge constructions with and without a copula do not differ with respect to the phenomena Maienborn discusses (temporal modification, interpretation of degree modifiers, anaphors, etc.). The more promising solution seems to consist in the assumption that in copulaless sentences, there is a phonetically empty yet syntactically visible copula which introduces the Kimian argument. But this solution doesn't seem to be an option for Russian. When construed with an overt copula, the following adjective may take instrumental case instead of nominative (15a). If an "empty" copula were syntactically present in copulaless constructions, it should show the same syntactic behavior in allowing the nominative-instrumental 
alternation, but it doesn't: in this case the nominative is obligatory (15b) (Unbegaun 1984: 287-288, Stassen 2001: 574). Thus, Russian seems to suggest that the state argument is introduced by the adjective or noun, and not by the copula. ${ }^{15}$
a. On
byl
he. MASC.SG.NOM was
molod-ym
young-MASC.SG.INSTR
'He was young'
b. *On
molod-ym
he. MASC.SG.NOM young-MASC.SG.INSTR
'He is young'

(from Nichols 1981: 292)

These short remarks on different types of languages suggest that Maienborn's assumption that it is the copula which introduces the Kimian argument and not the lexical item following it does not have broad cross-linguistic validity. It would, of course, take a larger effort to show in detail how the phenomena discussed by Maienborn, in particular the ones that depend on a state argument, are distributed in these languages.

\section{On predicative, attributive, and appositional uses of adjectives}

The previous section has raised some doubts about the validity of the copula solution. In this section, I will show that even in German there are a number of phenomena for which the copula solution won't work. Maienborn's central arguments for introducing state arguments are (i) that they allow temporal modifiers to be treated as intersective predicates (as is common practice in event semantics), (ii) that the dabei-

15 In Russian as well as in Polish, this particular distribution of case in predicative position affects adjectives as well as nouns. The case alternation is tied to a semantic difference which is to some degree related to stage / individual level contrasts. This seems to hold for Polish more than for Russian, where the semantic function of the case alternation is more obscure (cf. the discussion in Stassen 2001: 574ff). This is not relevant for my point here, though. 


\section{Stefan Engelberg}

construction serves to relate states / events, and (iii) that there is anaphoric reference to states. But these options are also open for adjectives which occur without the copula, namely adjectives in attributive and appositional constructions.

All the types of temporal expressions that Maienborn treats as state modifiers in copula constructions (16a) also appear with attributive (16b) or appositional (16c) adjectives:

(16) a. Jamaal war gestern / seit dem Morgen / zweimal / Jamaal was yesterday / since the morning / twice / tagelang wütend for.days furious

b. der gestern / seit dem Morgen / zweimal / tagelang the yesterday / since the morning / twice / for.days wütende Jamaal furious Jamaal

c. Jamaal, gestern / seit dem Morgen / zweimal / tagelang Jamaal yesterday / since the morning / twice / for.days wütend, furious

The same holds for the dabei-construction:

(17) a. der Tag war kalt und dabei regnerisch 'the day was cold and "there-at" rainy'

b. der kalte und dabei regnerische Tag "the cold and "there-at" rainy day'

c. der Tag, kalt und dabei regnerisch, 'the day, cold and "there-at" rainy,'

Even anaphoric reference is possible in non-predicative constructions, but this is more restricted for syntactic reasons:

(18) Jamaal, aufgeregt und hektisch - und das seit Tagen -, 'Jamaal, excited and hectic - and that for days -,'

Considering the data in this section and the previous one, it seems more promising to shift the lexical source of the state argument to the postcopula predicates. Since Maienborn doesn't provide many arguments in favor of the state-introducing function of the copula, I think that her 
otherwise very convincing argumentation would not loose any of its strength by assuming the following: ${ }^{16}$
a. wütend:
$\lambda \mathrm{x} \lambda \mathrm{z}[\mathrm{z} \approx[$ furious $(\mathrm{x})]]$
b. sei-:
$\lambda \mathrm{P} \lambda \mathrm{y}[\mathrm{P}(\mathrm{y})]$; for $\mathrm{P}$ as a predicate of the type $\left\langle\mathrm{e}^{\mathrm{i}}\left\langle\mathrm{e}^{\mathrm{z}}, \mathrm{t}\right\rangle\right\rangle^{17}$
c. wütend sei-: $\lambda y \lambda z[z \approx[$ furious $(y)]]$

Under these assumptions, we could account for the facts that (i) copula constructions in German are always stative, (ii) that eventuality denoting expressions as in (20) are excluded from copula constructions, and (iii) that temporal adverbials, the dabei-construction and, partly, anaphoric reference to states not only occur in the predicative domain, but also in attributive and appositional ones. ${ }^{18}$

(20) a. der schnell abfahrende Zug

the fast.ADV departing train

b. *Der Zug ist schnell abfahrend the train is fast.ADV departing

\section{Conclusion}

After having assembled a few rather critical remarks about some of Maienborn's assumptions, I feel obliged to say that I strongly agree with most of what Maienborn says about stative expressions. That is to say, the distinction between Davidsonian states and Kimian states is convincing and well motivated by the phenomena discussed. In particular, I want to emphasize that I consider the discussion of the nature of the

16 As far as I can see, the only argument in favor of the copula solution pertains to the avoidance of an infinite regress of state predications. Maybe I don't fully appreciate her point, but I don't see in how far representations as in (19) would be in danger to set off such a regress, in particular under the rather coarse-grained conception of Kimian states I suggested in section 2.

$17 e^{z}$ stands for a an entity of the sort 'Kimian state', $e^{i}$ for an entity of the ontological sort 'non-situational individual'.

18 It is of course still another question how state arguments in the attributive domain get bound. 
ontological sorts proposed a crucial methodological step that enhances the empirical value of the theory considerably. It prevents the introduction of referential arguments merely for the grounds that it is convenient for the semantic derivation. Instead, it preserves the idea that referential arguments are not only a useful anchor for intersective modification and other semantic devices, but are also the link between language and what language is about (cf. Engelberg 2001).

Not surprisingly, ontological considerations about states are a rather difficult matter. In particular, to achieve an empirically useful degree of precision with respect to the question of what a Kimian state is, one would have to show what counts as $P$, the property that constitutes the state. My remarks in section 2 were aimed at showing that $P$ cannot simply be "whatever follows the copula", but that states are instead probably quite a bit coarser than that.

Apart from that, my severest doubts pertain to the claim that it is the copula that introduces the state argument. Even if the copula solution does not lead to wrong semantic representations of German copula constructions, it doesn't appear to be compatible with several phenomena in the languages Maienborn discusses and in other - even typologically similar - languages. On the other hand, I don't think that Maienborn's main theoretical achievements would be diminished if we opt for the idea that the state argument is introduced by the post-copula predicates and not by the copula itself.

University of Wuppertal engelb@uni-wuppertal.de

\section{References}

Bennett, Jonathan (1988). Events and their Names. Indianapolis, Cambridge: Hackett.

Bhat, D. N. S. (1994). The Adjectival Category. Criteria for Differentiation and Identification. Amsterdam, Philadelphia: Benjamins.

Bhat, D. N. S. and M. S. Ningomba (1997). Manipuri Grammar. München, Newcastle: LINCOM.

Bunye, Maria V. R. and Elsa P. Yap (1971). Cebuano Grammar Notes. Honolulu: University of Hawaii Press.

Dixon, R. M. W. (1994). Adjectives. In The Encyclopedia of Language and Linguistics, Vol. 1, Ronald E. Asher (ed.), 29-35. Oxford et al.: Pergamon. 
Eckardt, Regine (2000). Causation, Contexts, and Event Individuation. In Speaking of Events, James Higginbotham, Fabio Pianesi, and Achille C. Varzi (eds.), 105-121. New York, Oxford: Oxford University Press.

Engelberg, Stefan (2000). Verben, Ereignisse und das Lexikon. Tübingen: Niemeyer.

- (2001). Immunisierungsstrategien in der lexikalischen Ereignissemantik. In Ereignisstrukturen, Johannes Dölling and Tatjana Zybatov (eds.), 9-33. Leipzig: Institut für Linguistik der Universität Leipzig.

Kim, Jaegwon (1969). Events and their Descriptions: Some Considerations. In Essays in Honor of Carl G. Hempel. A Tribute on the Occasion of his Sixty-Fifth Birthday, Nicholas Rescher (ed.), 198-215. Dordrecht: Reidel.

- (1976). Events as Property Exemplifications. In Action Theory. Proceedings of the Winnipeg Conference on Human Action, Held at Winnipeg, Manitoba, Canada, 9-11 May 1975, Myles Brand and Douglas Walton (eds.), 159-177. Dordrecht, Boston: Reidel.

Namai, Kenichi (2002). The Word Status of Japanese Adjectives. Linguistic Inquiry 33: 340-349.

Nichols, Johanna (1981). Predicate Nominals: A Partial Surface Syntax of Russian. Berkeley: University of California Press.

Ohkado, Masayuki (1991). On the Status of Adjectival Nouns in Japanese. Lingua 83: $67-82$.

Shibatani, Masayoshi (1990). The Languages of Japan. Cambridge: Cambridge University Press.

Stassen, Leon (2001). Nonverbal Predication in the Circum-Baltic Languages. In The Circum-Baltic Languages. Typology and Contact. Vol. 2: Grammar and Typology, Östen Dahl and Maria Koptjevskaja-Tamm (eds.), 569-590. Amsterdam, Philadelphia: Benjamins.

Unbegaun, B. O. (1984). Russian Grammar. Oxford: Clarendon. 
Bereitgestellt von | Institut für Deutsche Sprache (IDS) Bibliothek Angemeldet | 193.196.8.102

Heruntergeladen am | 16.04.13 14:01 